\title{
Role of Oral Intake on Intestinal Adaptation after Small Bowel Resection in Growing Rats
}

\author{
CLAUDE L. MORIN, (34) VICTOR LING, AND MICHELINE VAN CAILLIE \\ Pediatric Research Center and Department of Pediatrics, Division of Gastroenterology, Sainte-Justine Hospital \\ and University of Montreal, Montreal, Quebec, Canada
}

\section{Summary}

Fifty percent resection of the proximal small intestine was performed on growing male Sprague-Dawley rats which were then fed either orally (po) or intravenously (iv), with a liquid elemental diet. After 8 days, gut and mucosal weight, DNA, protein, sucrase, enterokinase, and alanine uptake were measured in the small intestine divided into three segments. Rates of weight gain were similar in the two groups (Fig. 1). Gut and mucosal weights (Fig. 2) and mucosal protein, DNA, and sucrase per $\mathrm{cm}$ intestine (Figs. 3 and 4$)$ were all higher $(P<$ 0.01 ) in the po group in all segments of the small intestine. However, protein, DNA, and sucrase per $g$ mucosa were not different in the two groups. In contrast, the specific transport activity (distribution ratio) of alanine was increased $(P<0.01)$ in the iv group whereas uptake per $\mathrm{cm}$ was similar (Fig. 5).

These results emphasize the importance of oral nutrition to the adaptation of the remaining gut in growing rats after proximal resection. On the other hand, the increased specific transport activity in parenteral feeding indicates that absorptive function at the cellular level may be independent of oral intake.

\section{Speculation}

After intestinal resection, parenteral nutrition should be supplemented with an elemental oral diet as soon as possible in order to optimize adaptation. Gastrointestinal hormones released by food or dependence on luminal sustenance may play an important role in the adaptive process.

After resection of the small intestine, the remaining portion undergoes both structural $(2,17,24)$ and functional $(6,7,30)$ adaptive changes. There is an increase in the epithelial cell population (hyperplasia) and consequently an increased function per unit length in the residual bowel (5). The value of total parenteral feeding in short bowel syndrome is well established and a widely used technique (8). However, studies now show that in normal rats, adequately nourished parenterally, the lack of oral intake leads to severe atrophy of the small intestine similar to that occurring in starvation $(14,18)$.

The following study compares the effects of oral and parenteral feeding on gut growth and parameters of function after proximal intestinal resection in growing rats.

\section{MATERIALS AND METHODS}

\section{PREPARATION OF ANIMALS}

Fifty percent resection of the proximal small intestine was performed on growing male Sprague-Dawley rats of 145-155 g body wt. These were then divided into two groups to be fed either orally (po) or intravenously (iv). Surgery was performed under pentobarbital anesthesia $(4.3 \mathrm{mg} / 100 \mathrm{~g})$. The small intestine from the ligament of Treitz to the ileocecal valve was exteriorized through a small midline incision and measured.
Intestine was then excised starting from $10 \mathrm{~cm}$ distal to the ligament of Treitz. The stumps were reconnected end to end and replaced in the abdominal cavity. A Silastic catheter was inserted into the right jugular vein at a point just cephalic to the clavicle and pushed to the atrium. It was secured with ligatures on either side of the entry point and passed subcutaneously to exit through a stab wound between the scapulae. A metal harness and infusion apparatus similar to that described by Steiger et al. (26) was then fitted to the rat. In order to lighten the harness assembly, a small diameter Tygon tube (Norton Co., Akron, $\mathrm{OH}$ ) with a loop tensioned by an elastic band was substituted for Steiger's protective wire coil. The animals were able to move freely in individual cages.

\section{NUTRITION}

The same liquid elemental diet was used for both po and iv feeding. Each liter of diet contained: $7.1 \mathrm{~g}$ nitrogen from $42 \mathrm{~g}$ amino acids (Travasol 10\%, Baxter Laboratories, Canada), 16 g lipid (Intralipid 10\%, Pharmacia, Canada), $300 \mathrm{~g}$ dextrose, $2.2 \mathrm{~g}$ calcium gluconate, and multivitamins (MVI, USV Pharmaceutical Corp., USA). Each milliliter supplied 1.4 cal. Rats fed po were harnessed as the iv animals and placed individually in cages where they had free access to saline or diet in a graduated drinking tube. Saline was given for the $24 \mathrm{hr}$ after surgery, after which liquid diet was supplied until $12 \mathrm{hr}$ before studies were made, when saline was again given. The same schedule was followed for the iv rats, with the amount infused determined from the average consumption of the po animals, which was $35 \mathrm{ml} /$ day.

\section{ANALYTIC METHODS}

After 8 days of po or iv feeding, animals were decapitated and their small intestines were removed as quickly as possible. After rinsing in cold saline, the total length under the tension of a $10-\mathrm{g}$ weight was measured. It was then divided into three segments, A, B, and C. Segment A was defined by the distance from the pylorus to the anastomosis. The length of gut from the anastomosis to the ileocecal valve was equally divided into segments B and C. Each segment was split lengthwise, cleaned by stroking with wet filter paper, sponged between damp gauze, and weighed. The mucosa was then scraped off with glass slides and weighed. An aliquot of mucosa from segment A was homogenized for enterokinase (EC 3.4.4.8) assay. Mucosa from each segment was wrapped in Parafilm (American Can Co., Greenwich, CT) and stored at $-70^{\circ}$ for other determinations. As it was critical in transport studies to use tissue in the freshest possible state, other animals in each group were used for that purpose only. Sections of gut were taken from segment $A$ for transport and weighing. The transport of L-alanine at $0.8 \mathrm{mM}$ was measured as intracellular accumulation in rings of everted intestinal tissue as previously described (21). Calculation of intracellular alanine was made from measurements of $\left[{ }^{14} \mathrm{C}\right]$ alanine content, total tissue fluid, and extracellular fluid (inulin space). This uptake of alanine is expressed in micromolar 
concentration per $\mathrm{cm}$ intestine as well as a distribution ratio between the intracellular and incubation medium concentrations: distribution ratio $=$ (counts $/ \mathrm{min} / \mathrm{ml}$ intracellular fluid) $/$ (counts $/ \mathrm{min} / \mathrm{ml}$ medium). A distribution ratio greater than 1.0 is presumed to represent uptake in excess of simple diffusion.

Enterokinase was measured by a method based on the twostep Kunitz (16) assay. Freshly scraped mucosa was homogenized in $80 \mathrm{vol}$ ice-cold water. To $1 \mathrm{ml}$ homogenate in a tube on ice, $0.10 \mathrm{ml} 0.10 \mathrm{M}$ maleate buffer at $\mathrm{pH} 6.0$ and $0.30 \mathrm{ml}$ water were added. The mixture was brought to $25^{\circ}$ and $0.10 \mathrm{ml}$ of a $0.005 \mathrm{M} \mathrm{CaCl}_{2}-0.001 \mathrm{M} \mathrm{HCl}$ solution containing $6 \mathrm{mg} / \mathrm{ml}$ trypsinogen (Worthington Biochemical Corp.) was added to initiate reaction. The reaction was allowed to proceed for $6 \mathrm{~min}$. Next $0.50 \mathrm{ml}$ of this mixture was added to $2.5 \mathrm{ml} \mathrm{N}$-benzoylDL-arginine-p-nitroanilide- $\mathrm{HCl}$ solution for measurement of trypsin (EC 3.4.4.4) according to the method of Erlanger $e t$ al. (10). After stopping the reaction with $0.50 \mathrm{ml} 30 \%$ acetic acid, the tube was centrifuged and the $O D$ read at $410 \mathrm{~nm}$. This method was found to give linear responses with crude homogenate to OD 0.35 . Enterokinase activity was calculated in units according to the following: 1 unit trypsin is the activity that hydrolyzes $1 \mu \mathrm{mol}$ benzoyl-DL-arginine- $p$-nitroanilide- $\mathrm{HCl} /$ $\mathrm{min}$, and 1 unit enterokinase is the activity that activates 1 unit trypsin/min. Protein was measured by Lowry's (20) using bovine albumin as standard. DNA was measured by Burton's method (3) with modifications according to Giles and Meyer (12). Sucrase (EC 3.2.1.26) was measured by Dahlqvist's method (9) and expressed as units (micromoles of substrate hydrolyzed per $\min$ at $37^{\circ}$ ).

All results were expressed as the means \pm SEM. Statistical analysis was carried out by unpaired Student's $t$-tests.

\section{RESULTS}

\section{BODY WEIGHT}

Rats were weighed after surgery and mean daily changes for both groups are shown in Figure 1. Although the po group lost more on the first day after resection, comparable rates of gain took hold from the second day, and the overall patterns were similar.

\section{GUT AND MUCOSAL WEIGHT}

Total lengths of gut were similar in both groups of animals. The length of the remaining gut of the oral group was $54.9 \pm$ $2.4 \mathrm{~cm}$ at sacrifice compared to $54.0 \pm 1 \mathrm{~cm}$ for the parenteral group (iv). Gut and mucosal weights are shown in Figure 2. These parameters were significantly higher $(P<0.01)$ in the po group in all three segments. The mean gut weight of the entire small bowel was $45 \%$ higher in the po group whereas mucosal

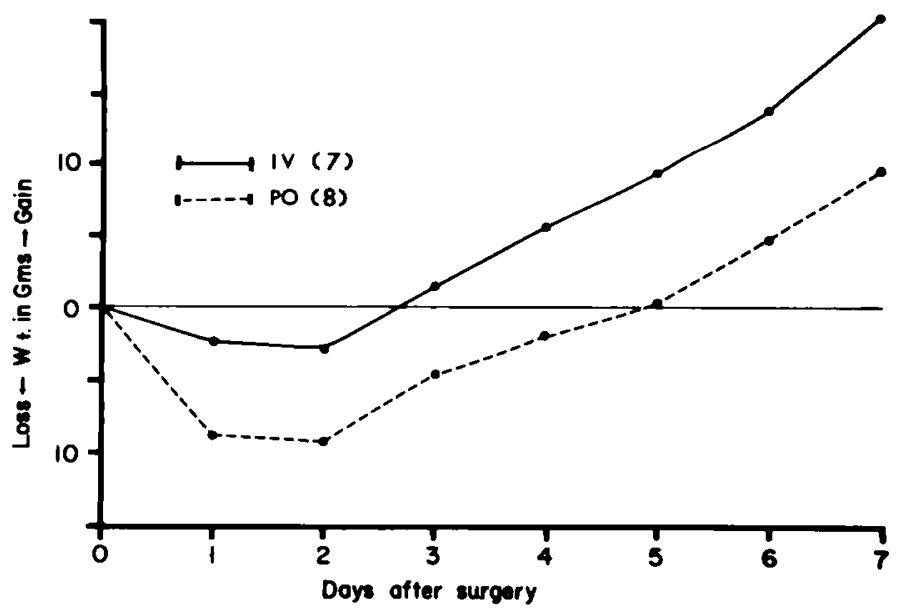

Fig. 1. Changes in weights of rats after resection. weight was $94 \%$ above the iv animals. This indicates that changes in the mucosa accounted for most of the difference.

\section{MUCOSAL PROTEINS AND DNA}

The differences in gut and mucosal weight were reflected in the mucosal protein and DNA content of the two groups (Fig. $3)$. The po group had significantly higher $(P<0.01)$ DNA and protein contents per $\mathrm{cm}$ throughout the small intestine. However, when protein and DNA results were expressed per $g$ mucosa, there were no differences in these parameters in any of the segments.

\section{SUCRASE AND ENTEROKINASE ACTIVITIES}

Sucrase and enterokinase activities per $\mathrm{cm}$ intestine are shown in Figure 4. The level of sucrase was significantly higher $(P<$ $0.01)$ in the po group in all segments. The mean enterokinase

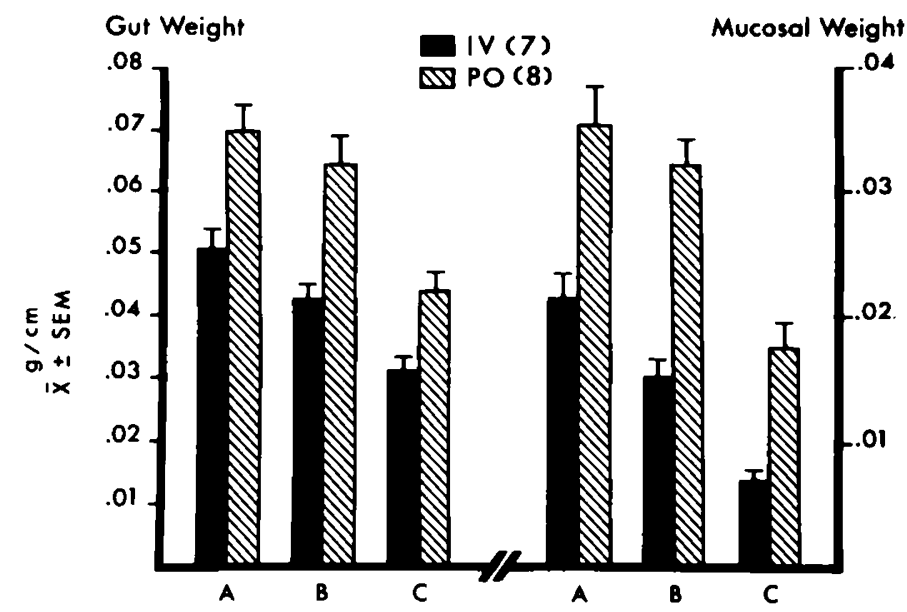

Fig. 2. Comparison of gut and mucosal weights of small intestine.

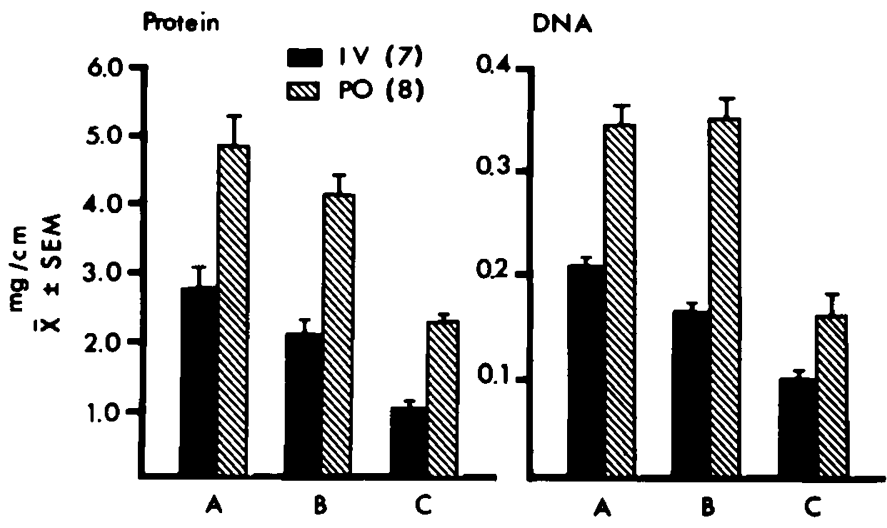

Fig. 3. Comparison of mucosal DNA and protein content per unit length of intestine.

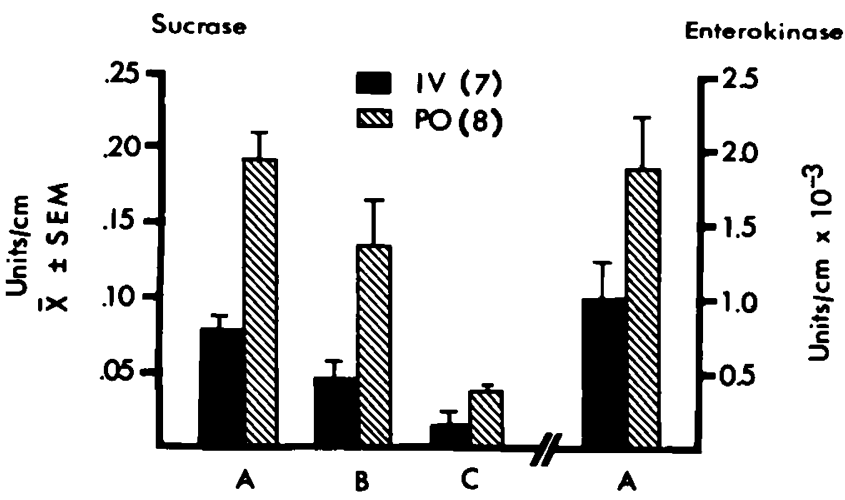

Fig. 4. Sucrase and enterokinase activities per unit length of intestine. 


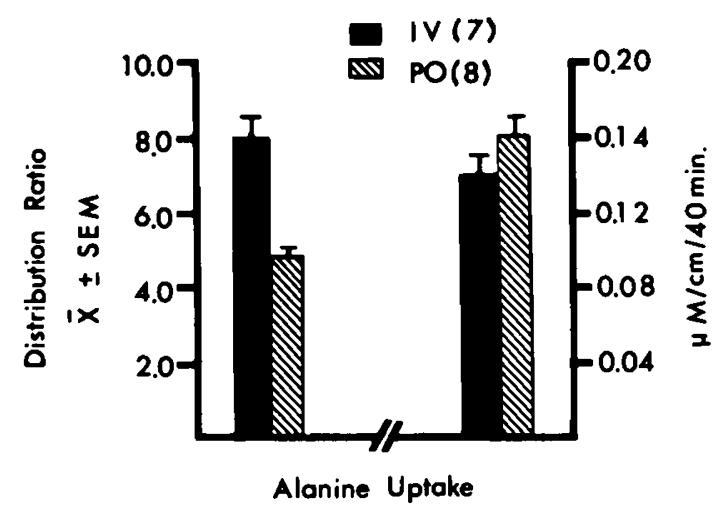

Fig. 5. Transport of alanine measured as specific transport activity (distribution ratio) and uptake in micromolar concentration per unit length of intestine in segment $A$ (mean \pm SEM).

activity was also higher in the po group but not statistically different because of large individual variations. However, the specific activity of both enzymes expressed either per g mucosa or mucosal protein or DNA, even though slightly increased in the po group, did not differ significantly.

\section{ALANINE UPTAKE}

Uptake of L-alanine into intestinal rings from segment A expressed per $\mathrm{cm}$ intestine and as a distribution ratio is shown in Figure 5. Tissue from iv group maintained a much higher $(P<$ 0.01 ) distribution ratio but the uptake per unit length of intestine was found to be nearly equal.

\section{DISCUSSION}

The results of this study emphasize the importance of oral nutrition for the development of both structural and functional adaptation in the remaining gut of growing rats after proximal intestinal resection. The present data also show that with nothing but parenteral nutrition, the resected animals have been maintained in excellent health with weight gain. The iv rats in fact weighed more than po rats, which may be accounted for by the smaller intake of the latter the first and second days after surgery. The importance of oral nutrition on intestinal adaptation after resection has been shown recently in dogs (11) and in mature rats (19). Although these data show the importance of oral intake on intestinal adaptation, the mechanisms whereby food is acting are not known. There are experimental data showing that factors present in biliary and pancreatic secretions (1), changes in blood flow (29), and trophic properties of the gastrointestinal hormones (13) may all contribute to the adaptive changes after intestinal resection (5). Oral intake could be the initial stimulus of these mechanisms. Among these, gastrin could be of importance. Johnson et al. (14) have shown that after a short period of intravenous feeding in normal rats there was a depletion of antral gastrin and marked mucosal hypoplasia. In a subsequent paper (15), they have shown that pentagastrin infusion in parenterally fed animals sustains gut mass as compared to controls. Furthermore, studies in man (27) and in animals (31) have reported hypersecretion of gastrin after massive intestinal resection. It appears, however, that the trophic action of infused pentagastrin in resected rats fed intravenously is limited to the proximal portion of the small intestine and differs in distribution and magnitude to the hyperplasia occurring after intraluminal feeding (23).

Increased activities of sucrase $(4,22)$ and enterokinase (22) per unit length of intestine after resection have been previously reported. The lack of oral food, as shown in this study, prevented similar changes in the iv animals. Levine $e t$ al. (18) have reported that in normal rats intravenous alimentation led to a significant fall in both total sucrase activity and sucrase specific activity compared to orally fed rats. The greater enzymatic content per $\mathrm{cm}$ intestine that we observed in the po group reflects mostly higher mucosal protein content since specific activity, even though increased, was not statistically different.

Most investigators $(11,22,25,30)$ have found an increase in absorptive function per unit length of intestine in the remaining gut after resection. However, there is either no change or even a decrease in the function of individual epithelial cells. The present study shows the opposite since the iv rats were able to maintain a much higher intracellular-extracellular concentration gradient of alanine as reflected by a much higher distribution ratio. In terms of overall uptake per unit length of gut, this was able to compensate for the lack of mucosal bulk in these animals, and this parameter was at the same level as in the po rats. Schanbacher et al. (28) have shown in abstract form similar results in a study comparing the intestinal uptake of glucose in orally fed normal rats with animals fed intravenously. An increased efficiency of substrate utilization by the intestine of iv rats was suggested. This could also indicate that after intestinal resection transport function at cellular level is independent of oral intake.

If the present results could be extrapolated to man, it suggests that children who undergo resection of the small intestine should be treated whenever possible by oral feeding.

\section{CONCLUSION}

The crucial role of oral feeding in the adaptation of the resected small intestine has been demonstrated in growing rats with an elemental diet. Compared to parenteral nutrition, mucosal mass was much higher, providing for higher total quantities of DNA, protein, and sucrase. In contrast, specific transport activity was increased in parenteral feeding, indicating independent compensation of absorptive function.

\section{REFERENCES AND NOTES}

1. Altman, G. G.: Influence of bile and pancreatic secretions on the size of the intestinal villi in the rat. Amer. J. Anat., 132: 167 (1971)

2. Booth, C. C., Evans, K. T., Menzies, T., and Street, D. F.: Intestinal hypertrophy following partial resection of the small bowel in the rat. Brit. J. Surg., 46: 403 (1959).

3. Burton, K.: A study of the conditions and mechanisms of the diphenylamine reaction for the colorimetric estimation of deoxyribonucleic acid. Biochem. J., 62: 315 (1956).

4. Bochenek, W. J., Narczewska, B., and Grzebieluch, M.: Effect of massive proximal small bowel resection on intestinal sucrase and lactase activity in the rat. Digestion, 9: 224 (1973).

5. Dowling, R. H.: Intestinal adaptation. N. Engl. J. Med., 288: 520 (1973).

6. Dowling, R. H., and Booth, C. C.: Functional compensation after small bowel resection in man. Lancet, ii: 146 (1966).

7. Dowling, R. H., and Booth, C. C.: Structural and functional changes following small intestinal resection in the rat. Clin. Sci., 32: 139 (1967).

8. Dudrick, S. J., and Ruberg, R. L.: Principles and practice of parenteral nutrition. Gastroenterology, 61: 901 (1971).

9. Dahlqvist, A.: A method for assay of intestinal disaccharidases. Anal Biochem. 7: 18 (1964).

10. Erlanger, B., Kokowsky, N., and Cohen, N.: The preparation and properties of two new chromogenic substrates of trypsin. Arch. Biochem. Biophys., 95: 271 (1961).

11. Feldman, E. J., Dowling, R. H., McNaughton, J., and Peters, T. J.: Effects of oral versus intravenous nutrition on intestinal adaptation after small bowel resection in the dog. Gastroenterology, 70: $712(1976)$.

12. Giles, K. W., and Meyers, A.: An improved diphenylamine method for the estimation of deoxyribonucleic acid. Nature, 206: 93 (1965).

13. Johnson, L. R.: The trophic action of gastrointestinal hormones. Gastroenterology, 70: 278 (1976).

14. Johnson, L. R., Copeland, E. M., Dudrick, S. J., Lichtenberger, L. M., and Castro, G. H.: Structural and hormonal alterations in the gastrointestinal tract of parenterally fed rats. Gastroenterology, 68: 1177 (1975).

15. Johnson, L. R., Lichtenberger, L. M., Copeland, E. M., Dudrick, S. J.. and Castro, G. H.: Action of gastrin on gastrointestinal structure and function. Gastroenterology, 68: 1184 (1975).

16. Kunitz, M.: Formation of trypsin from crystalline trypsinogen by means of enterokinase. J. Gen. Physiol., 22: 429 (1939).

17. Loran, M. R., and Althausen, T. L.: Cellular proliferation of intestinal epithelia in the rat two months after partial resection of the ileum. J. Biophys. Biochem. Cytol., 7: 667 (1960).

18. Levine, G. M., Deren, J. J., Steiger, E., and Zinno, R.: Role of oral intake in maintenance of gut mass and disaccharide activity. Gastroenterology, 67: 975 (1974). 
19. Levine, G. M., Deren, J. J., and Yezdimir, E.: Small-bowel resection: oral intake is the stimulus for hyperplasia. Digest. Dis., 21: 542 (1976).

20. Lowry, O. H., Rosebrough, N. J., Farr, A. L., and Randall, R. J.: Protein measurement with the Folin phenol reagent. J. Biol. Chem, 193: 265 (1951).

21. Ling, V., and Morin, C. L.: Inhibition of amino acid transport in rat intestinal rings by tetracycline. Biochim. Biophys. Acta, 249: 252 (1971).

22. McCarthy, D. M., and Kim, Y. S.: Changes in sucrase, enterokinase, and peptide hydrolase after intestinal resection. J. Clin. Invest., 52: 942 (1973).

23. Morin, C. L., Ling, V., and Bourassa, D.: Effect of pentagastrin on the small intestine after resection (Abstr.). Gastroenterology, 72: 1105, 1977.

24. Nygaard, K.: Resection of the small intestine in rats. III. Morphological changes in the intestinal tract. Acta Chir. Scand., 133: 233 (1967).

25. Rodgers, J. B., and Bochenek, W.: Localization of lipid reesterifying enzymes of the rat small intestine: Effects of jejunal removal on ileal enzyme activities. Biochim. Biophys. Acta, 202: 426 (1970).

26. Steiger, E., Vars, H. M., and Dudrick, S. J.: A technique for long term intravenous feeding in unrestrained rats. Arch. Surg., 104: 330 (1972).

27. Strauss, E., Gerson, C. D., and Yalow, R. S.: Hypersecretion of gastrin associated with the short bowel syndrome. Gastroenterology, 66: 175 (1974).

Copyright (1) 1978 International Pediatric Research Foundation, Inc. $0031-3998 / 78 / 1204-0268 \$ 02.00 / 0$
28. Schanbacher, L. M., Copeland, E. M., Dudrick, S. J., Johnson, L. R., and Castro, G. H.: Intestinal uptake of glucose in parenterally nourished rats (Abstr.). Gastroenterology, 68: 981 (1975).

29. Touloukian, R. J., Ileal blood flow preceding compensatory intestinal hypertrophy. Ann. Surg., 175: 320 (1972).

30. Weser, E., and Hernandez, M. H.: Studies of small bowel adaptation after intestinal resection in the rat. Gastroenterology, 60:69 (1971).

31. Wickborn, G., Landor, J. H., Buskin, F. L., and McGuigan, J. E.: Changes in canine gastric acid output and serum gastrin levels following massive small intestinal resection. Gastroenterology, 69: 448 (1975).

32. This research was presented in part at the combined meeting of the American Pediatric Society and the Society for Pediatric Research, St. Louis, April 1976.

33. This research was supported by the Medical Research Council of Canada (Grant MA-3320), and by the Fondation Justine-Lacoste-Beaubien.

34. Requests for reprints should be addresssd to: C. L. Morin, M.D. SainteJustine Hospital, 3175 St. Catherine Road, Montreal, H3T 1C5, P.Q.

35. Received for publication March 7, 1977

36. Accepted for publication July 19, 1977. 